\title{
Characterisation of background dose-rates for marine environments
}

\author{
H. Thørring, J.E. Brown and A. Hosseini \\ Norwegian Radiation Protection Authority, PO Box 55, 1332 Østerås, Norway
}

\begin{abstract}
Environmental risk assessment methodologies often require background dose-rates for wild flora and fauna to be derived in a robust and transparent way. To facilitate this task, information can be organised around reference organisms (ROs), entities that can be used as representatives of the broader ecosystem. In this study, generic datasets have been collated on levels of naturally occurring radionuclides in sediments, seawater and ROs for marine ecosystems. In some cases, data gap filling methods have been required owing to a paucity of information. Once full datasets have been acquired, dose conversion coefficients (DCCs) can be applied and dose-rate calculations can be performed probabilistically allowing the variability in the underlying datasets to be accounted for. Unweighted absorbed dose-rates for marine reference organisms lie between $0.02-1.2 \mu \mathrm{Gy} \mathrm{h}^{-1}$, whereas weighted dose-rates fall in the range $0.08 \mu \mathrm{Gy} \mathrm{h}^{-1}$ to $8.8 \mu \mathrm{Gy} \mathrm{h}^{-1}$. Except for the special case of sea anemones/corals, the most important nuclides for the total dose-rates are ${ }^{210} \mathrm{Po}$ and ${ }^{226} \mathrm{Ra}$ for heterotrophic ROs (i.e. all vertebrate and invertebrate animals), whereas ${ }^{226} \mathrm{Ra}$ and ${ }^{228}$ Th contribute most for autotrophic ROs (i.e. macroalgae, phytoplankton and aquatic plants). In addition, ${ }^{40} \mathrm{~K}$ has a considerable impact on unweighted dose-rates for all ROs. Non-parametric statistical tests have been applied to show whether there are differences between activity concentrations data for ROs and ICRPdefined Reference Animals and Plants (RAPs).
\end{abstract}

\section{INTRODUCTION}

Along with data concerning the dose-rates at which effects are observed for selected endpoints in studied plants and animals, the regional background dose-rate might be considered as an important reference point for establishing the severity of calculated environmental exposures to radiation [1]. Using background as a reference point is in line with the concept of derived consideration levels as advocated by initial thoughts on this subject by the International Commission on Radiological Protection (ICRP) [2]. This might be organised in such a way that dose-rates calculated to be only fractions of their background might be considered to be trivial or of low concern; those within the normal background range might need to be considered carefully; and those that were one, two, three or more orders of magnitude greater than background would be of increasingly serious concern because of their known adverse effects on individual fauna and flora [1]. Furthermore, comprehensive data on background doserates could clearly be used to provide better estimates of incremental dose-rates in cases where the source of contamination is Technological Enhanced Naturally Occurring Radioactive Material (TENORM).

In earlier work, background dose-rates for marine environments have been derived for a suite of reference organisms (ROs), i.e. organisms representing the broader ecosystem that provide a basis for radiation dose-rates estimations to the environment (see [3]). This previous study has been expanded within the current review to cover more data, in general, and the list of reference organisms has been updated in accordance with the work done within the EC funded project "ERICA" [4]. Furthermore, a larger suite of radionuclides have been considered $\left({ }^{14} \mathrm{C},{ }^{3} \mathrm{H},{ }^{40} \mathrm{~K},{ }^{87} \mathrm{Rb},{ }^{238} \mathrm{U},{ }^{234} \mathrm{Th},{ }^{234} \mathrm{U},{ }^{230} \mathrm{Th}\right.$, ${ }^{226} \mathrm{Ra},{ }^{210} \mathrm{~Pb},{ }^{210} \mathrm{Po},{ }^{232} \mathrm{Th},{ }^{228} \mathrm{Ra},{ }^{228} \mathrm{Th},{ }^{235} \mathrm{U}$ ). Progeny with half lives $<10$ days are according to ERICA methodology included in the DCC of the "parent" nuclide. In addition, our study has considered the ICRPs Reference Animal or Plant (RAP) defined as "a hypothetical entity, with assumed basic characteristics of a specific type of animal or plant, as described to the generality of the taxonomic 
level of the Family, with precisely defined anatomical, physiological and life history properties that can be used for the purposes of relating exposure to dose and dose to effects for that type of living organism" [5]. For marine systems, RAPs consist of flatfish, crab, brown seaweed and trout (salmonid). The absorbed dose-rates reported in the following were derived using the ERICA Assessment Tool [6].

\section{MATERIALS AND METHODS}

The basic components of information required to derive dose-rates to marine ROs using the ERICA Assessment Tool are: (i) the activity concentrations of radionuclides in ROs, sea water and sediments; (ii) Dose Conversion Coefficients mapping these activity concentrations onto a dose-rate and (iii) occupancy factors defining the time spent by ROs at various locations within their habitats (i.e. water surface, water column, sediment-water interface, sediment core) in order to provide parameters for external dose calculations. External and internal dose-rates were calculated using Equations (1) and (2), resspectivly. Total dose-rates are derived by the addition of internal and external components of dose-rate.

$$
\dot{\mathrm{D}}_{\mathrm{ext}}^{\mathrm{j}}=\sum_{\mathrm{z}} \mathrm{v}_{\mathrm{z}} \sum_{\mathrm{i}} \mathrm{C}_{\mathrm{zi}}^{\mathrm{ref}} * \mathrm{DCC}_{\mathrm{ext}, \mathrm{zi}}^{\mathrm{j}}
$$

where,

$v_{z}$ is the occupancy factor, i.e. fraction of the time that the reference organism $\mathrm{j}$ expends at a specified location $\mathrm{z}$ in its habitat

$C_{z i}^{r e f}$ is the average concentration of the radionuclide $\mathrm{i}$ in the reference media of a given location $\mathrm{z}$ (Bq kg ${ }^{-1}$ (sediment) or $\mathrm{Bq}^{-1}$ (water))

$D C C_{e x t, z i}^{j}$ is the dose conversion coefficient for external exposure defined as the ratio between the average activity concentration of the radionuclide $i$ in the reference media corresponding to the location $\mathrm{z}$ and the dose rate to the reference organism $\mathrm{j}\left(\mu \mathrm{Gyh}^{-1}\right.$ per Bq kg${ }^{-1}$ or Bq $\left.l^{-1}\right)$

$$
\dot{\mathrm{D}}_{\mathrm{int}}^{\mathrm{j}}=\sum_{\mathrm{i}} \mathrm{C}_{\mathrm{i}}^{\mathrm{j}} * \mathrm{DCC}_{\mathrm{int}, \mathrm{i}}^{\mathrm{j}}
$$

where,

$C_{i}^{j}$ is the activity concentration of the radionuclide $\mathrm{i}$ in the reference organism $\mathrm{j}\left(\mathrm{Bq} \mathrm{kg}^{-1}\right.$ fresh weight) $D C C_{i n t, i}^{j}$ is the radionuclide-specific dose conversion coefficient for internal exposure defined as the ratio between the activity concentration of the radionuclide $i$ in the reference organism $j$ and the doserate to the RAP $\left(\mathrm{Gy} \mathrm{h}^{-1}\right.$ per $\mathrm{Bq} \mathrm{kg}^{-1}$ fresh weight).

To evaluate the likely range of total dose-rate to each class of organism, appropriate probability distribution functions (pdfs) were assigned to activity concentrations, following rules derived from the application of the Maximum Entropy Method [7]. This is essentially a statistical method for assigning a distribution of maximum logical uncertainty with respect to a given parameter, consistent with the amount of statistical information provided.

In view of the disparity of information available, activity concentrations in water and sediments have been reported as typical, minimum and maximum on a reference by reference basis. This has allowed an overall typical value to be derived on the synthesis of the individual values. Strictly speaking, the maximum entropy principle dictates that when a mean and a range are available, a beta distribution should be used. However, in view of the facts that typical values (as oppose to mean values) only were available and that the suite of distribution functions supported by the ERICA Assessment Tool does not accommodate the beta distribution (see [6]), a uniform distribution was considered to be appropriate. In the cases where the only available statistical information was mean (or a typical value), an exponential distribution was applied. 
The activity concentration data for marine biota were treated in a slightly different way. Statistical information for a particular study/paper was collated (i.e. mean, standard deviation, $n$ ). Data originally reported as "dry weight" or "ash weight" were converted to "fresh weight" using correction factors of 0.18 and 0.01 , respectively [8]. Furthermore, data conversions were made pertaining to specific organs or body parts to whole body parts where this was practicable. As the reporting format of the data differs between studies/papers, a coherent means of combining data is required to derive "overall" statistics for a RO. This involves the use of the sum and the sum of squares of values and the subsequent derivation of weighted means and variances as shown in [9]. Furthermore, severe data gaps were evident for some RO activity concentrations especially in the cases of (wading) bird, reptile, and sea anemone/true corals. There was also poor data coverage for polychaete worm, vascular plant, and mammal. In most cases, gaps were filled by using taxonomic analogues (e.g. using data from benthic mollusc to fill gaps for polychaete). This is in line with the approach outlined by [9]. An overview of data coverage along with data gap "filling methods" applied in our study is provided in Table 1.

Table 1. An overview of the data for natural radionuclides in marine organisms used in the present study. Greyscale codes are used to give an impression of the amount of data available. Numbers given for data gaps refer to "filling method": 1. Taxonomic analogue used (A: fish, B: benthic mollusc, C: macroalgae, D: mammal, E: crustacean, F: coelenterate; 2. Derived from ${ }^{238} \mathrm{U}$ using ratios taken from [13]; 3. Secular equilibrium with ${ }^{238} \mathrm{U}$ assumed; 4. Derived from water concentrations assuming a CR of unity.

\begin{tabular}{|c|c|c|c|c|c|c|c|c|c|c|c|c|}
\hline & Malg & Fish & Biv & Crust & Zoopl & Phytopl & Mam & Plant & Worm & Coral & Bird & Rept \\
\hline Po-210 & & & & & & & & $1 \mathrm{C}$ & & $1 \mathrm{E}$ & $1 \mathrm{D}$ & $1 \mathrm{D}$ \\
\hline $\mathrm{K}-40$ & & & & & & & & $1 \mathrm{C}$ & & $1 \mathrm{~F}$ & $1 \mathrm{D}$ & $1 \mathrm{D}$ \\
\hline $\mathrm{Pb}-210$ & & & & & & $1 \mathrm{C}$ & & $1 \mathrm{C}$ & $1 \mathrm{~B}$ & $1 \mathrm{~B}$ & $1 \mathrm{D}$ & $1 \mathrm{D}$ \\
\hline $\mathrm{Ra}-226$ & & & & & & & $1 \mathrm{~A}$ & & $1 \mathrm{~B}$ & $1 \mathrm{~B}$ & $1 \mathrm{~A}$ & $1 \mathrm{~A}$ \\
\hline $\mathrm{Th}-228$ & & & & & & & $1 \mathrm{~A}$ & & $1 \mathrm{~B}$ & $1 \mathrm{~B}$ & $1 \mathrm{~A}$ & $1 \mathrm{~A}$ \\
\hline $\mathrm{U}-238$ & & & & & & & $1 \mathrm{~A}$ & $1 \mathrm{C}$ & $1 \mathrm{~B}$ & & $1 \mathrm{~A}$ & $1 \mathrm{~A}$ \\
\hline $\mathrm{C}-14$ & & & & & & & $1 \mathrm{~A}$ & $1 \mathrm{C}$ & & $1 \mathrm{~F}$ & $1 \mathrm{~A}$ & $1 \mathrm{~A}$ \\
\hline $\mathrm{Th}-232$ & & & & & & & $1 \mathrm{~A}$ & $1 \mathrm{C}$ & $1 \mathrm{~B}$ & $1 \mathrm{~B}$ & $1 \mathrm{~A}$ & $1 \mathrm{~A}$ \\
\hline $\mathrm{Th}-230$ & & & & & & & $1 \mathrm{~A}$ & $1 \mathrm{C}$ & $1 \mathrm{~B}$ & $1 \mathrm{~B}$ & $1 \mathrm{~A}$ & $1 \mathrm{~A}$ \\
\hline $\mathrm{U}-234$ & & & & & 2 & 2 & $1 \mathrm{~A}$ & $1 \mathrm{C}$ & $1 \mathrm{~B}$ & 2 & $1 \mathrm{~A}$ & $1 \mathrm{~A}$ \\
\hline $\mathrm{U}-235$ & & & & & 2 & 2 & $1 \mathrm{~A}$ & $1 \mathrm{C}$ & $1 \mathrm{~B}$ & 2 & $1 \mathrm{~A}$ & $1 \mathrm{~A}$ \\
\hline $\mathrm{Rb}-87$ & & & & & $1 \mathrm{E}$ & $1 \mathrm{C}$ & $1 \mathrm{~A}$ & $1 \mathrm{C}$ & $1 \mathrm{~B}$ & $1 \mathrm{~B}$ & $1 \mathrm{~A}$ & $1 \mathrm{~A}$ \\
\hline $\mathrm{Ra}-228$ & & & $1 \mathrm{~A}$ & $1 \mathrm{~A}$ & $1 \mathrm{~A}$ & $1 \mathrm{C}$ & $1 \mathrm{~A}$ & & $1 \mathrm{~A}$ & $1 \mathrm{~A}$ & $1 \mathrm{~A}$ & $1 \mathrm{~A}$ \\
\hline $\mathrm{Th}-234$ & 3 & 3 & 3 & 3 & 3 & 3 & 3 & 3 & 3 & 3 & 3 & 3 \\
\hline $\mathrm{H}-3$ & 4 & 4 & 4 & 4 & 4 & 4 & 4 & 4 & 4 & 4 & 4 & 4 \\
\hline
\end{tabular}

\begin{tabular}{lll}
$\mathrm{N} \geq 20$ & $\mathrm{~N}<10 \quad \mathrm{~N}<20$ & Gaps \\
\hline
\end{tabular}

The data available for each RO were used to specify pdfs applying the following simple rules: (i) Where a mean and a standard deviation could be determined from the raw data being used to derive the parameter, a lognormal distribution was applied; (ii) where the only available statistical information was mean (or derived value), an exponential distribution was applied [6].

Once input data have been assigned suitable distributions the ERICA Tool [6] allows the application of Monte Carlo probabilistic simulations in order to propagate the uncertainties in the inputs and parameters through the model.

All DCCs used in this study are ERICA specific values for marine ROs provided as defaults in the ERICA Tool [6]. In order to take account of the biological effectiveness of different types of ionising radiation the default radiation weighting factors of 10 for alpha, 3 for low energy beta and 1 for other beta/gamma have been used in line with the provisional, illustrative values, used by [10]. The alpha radiation weighting factor of 10 applied in this work is consistent with the upper bound on the range of variation reported by [11] for $\alpha$-radiation weighting factors in relation to population relevant deterministic endpoints (mainly mortality). Nonetheless, it should be noted that the final choice of radiation weighting factor for alpha particles will depend on the selection of reference organism, end-point and dose (or dose-rate) range [12] and that other values might be equally appropriate.

Simple assumptions were made in relation to the occupancy factors for each type of RO: (i) mammals and (wading) birds are continually at the water surface; (ii) phytoplankton, zooplankton, pelagic fish and 
reptiles spend their entire time in the water column (iii) macroalgae, vascular plants, sea anemone/coral, crustaceans, benthic molluscs and benthic fish are solely at the sediment-water interface, whereas polychaetes are always buried in the sediments. A 50\% correction from dry to fresh weight sediments was assumed in connection with external dose-rate calculations.

\section{RESULTS AND CONCLUSIONS}

Total unweighted and weighted dose-rates to all ERICA marine reference organisms are shown in Table 2. It should be noted that the 5th and 95th percentile values obtained from the probabilistic simulation (using 10000 runs) should be interpreted as indicative of the range of dose-rates likely to be experienced by different ROs; it does not represent a statistically valid estimate of the doserate distribution, because sufficient data to permit adequate empirically based statistical distributions of radionuclide concentrations in organisms and their media do not exist.

Table 2. Total unweighted and weighted dose-rates $(\mu \mathrm{Gy} / \mathrm{h})$ from natural nuclides to marine reference organisms.

\begin{tabular}{|l|c|c|c|c|c|c|}
\hline \multirow{2}{*}{ Reference organism } & \multicolumn{3}{|c|}{ Unweighted } & \multicolumn{3}{c|}{ Weighted } \\
\cline { 2 - 7 } & Mean & Median & Range* & Mean & Median & Range* \\
\hline Phytoplankton & 0.09 & 0.04 & $0.02-0.20$ & 0.79 & 0.38 & $0.13-2.0$ \\
\hline Pelagic fish & 0.13 & 0.07 & $0.02-0.40$ & 1.0 & 0.42 & $0.08-3.7$ \\
\hline Zooplankton & 0.17 & 0.11 & $0.04-0.53$ & 1.6 & 0.94 & $0.25-5.2$ \\
\hline Mammal** & 0.21 & 0.13 & $0.05-0.61$ & 1.8 & 1.0 & $0.23-5.8$ \\
\hline Reptile** & 0.21 & 0.16 & $0.04-0.56$ & 1.8 & 1.3 & $0.18-5.2$ \\
\hline Wading) bird** $^{*}$ & 0.21 & 0.16 & $0.03-0.56$ & 1.8 & 1.3 & $0.17-5.3$ \\
\hline Benthic fish & 0.37 & 0.34 & $0.11-0.67$ & 1.3 & 0.68 & $0.24-3.9$ \\
\hline Crustacean & 0.41 & 0.36 & $0.13-0.84$ & 1.8 & 0.99 & $0.33-5.9$ \\
\hline Macroalgae & 0.43 & 0.43 & $0.20-0.66$ & 1.1 & 1.0 & $0.60-1.7$ \\
\hline Vascular plant** & 0.46 & 0.45 & $0.22-0.72$ & 1.6 & 1.4 & $0.75-3.0$ \\
\hline Benthic mollusc & 0.49 & 0.47 & $0.22-0.85$ & 2.5 & 2.0 & $0.98-5.6$ \\
\hline Polychaete worm** & 0.68 & 0.68 & $0.25-1.1$ & 1.6 & 1.6 & $0.94-2.5$ \\
\hline Sea anemone/coral** & 0.73 & 0.71 & $0.36-1.2$ & 4.6 & 4.2 & $1.9-8.8$ \\
\hline
\end{tabular}

$*$ Range is defined by the $5^{\text {th }}$ and $95^{\text {th }}$ percentiles as derived from the probabilistic simulations.

**General lack of data on internal concentrations - filling methods used for most radionuclides (see Table 1).

As shown in Table 2, sea anemone/coral constitute the most exposed biota group (as defined by both the average value and maximum in the range) reflecting the fact that uranium is a relatively important contributor to overall exposure in this case due to enhanced internal concentrations in corals compared to the other ROs. However, due to severe lack of data for this RO - derived values have been used for several important nuclides including ${ }^{210} \mathrm{Po}$ - more information is required to confirm whether sea anemones/corals in fact constitute a more exposed group than other reference organisms.

Except for the special case of sea anemones/corals, the most important nuclides for the total-doserates are ${ }^{210} \mathrm{Po}$ and ${ }^{226} \mathrm{Ra}$ for heterotrophic ROs (i.e. all vertebrate and invertebrate animals), whereas ${ }^{226} \mathrm{Ra}$ and ${ }^{228} \mathrm{Th}$ contribute most for autotrophic ROs (i.e. macroalgae, phytoplankton and aquatic plants). In addition, potassium-40 is of importance especially in connection with unweighted dose-rates (as exemplified in Figure 1).

Generally, external dose-rates are of significance only for benthic ROs (i.e. organisms inhabiting the sediments or the sediment-water interface as specified by the occupancy factors used in our study). For these ROs external dose-rates contribute in average 55\% of the total unweighted dose-rate - about $35 \%$ for sea anemone/coral and up to $80 \%$ for sediment dwelling polychaetes. The corresponding figures for weighted dose-rates are 15\% (ranging from 5 to 35\%). Radium-226 stands for approximately 80-90\% of the external dose-rate to benthic reference organisms. In contrast, the external component to pelagic organisms is about $1 \%$ of the total (or less) considering both unweighted and weighted dose-rates. 

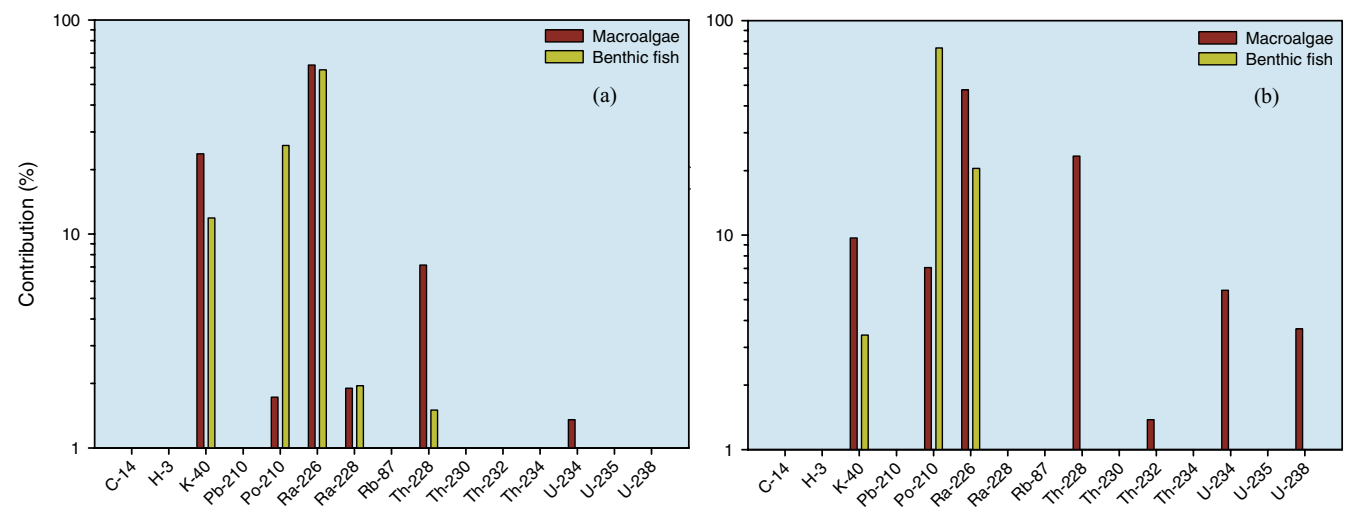

Figure 1. Percentage contribution (based on mean values) from various radionuclides to total dose-rates in two selected reference organisms: (a) Unweighted dose-rates; (b) weighted dose-rates.

Finally, the non-parametric Mann-Whitney test has been applied in order to determine whether data sets corresponding specifically to RAPs (as defined by the ICRP) are statistically different from more generic datasets, comprised of all species under the corresponding ERICA reference organism (minus the RAP data). The null hypothesis is that these 2 samples have been taken from a common population so that there is no consistent difference between the 2 sets of data. Since there is no hypothesis concerning whether the mean rank of one population is greater or less than the other, a two tailed test was considered appropriate. A decision was made to consider only the activity concentrations of ${ }^{210} \mathrm{Po}$ in flatfish and crab in this preliminary analysis primarily because the contributions of ${ }^{210}$ Po to the weighted internal dose received are known to be substantial for these 2 organisms.

In the comparison of flatfish (pleuronectes spp.) against all other types of fish, the null hypothesis (as stated above) could not be rejected at the 0.05 significance level. There is no strong evidence to suggest that pleuronectes spp. exhibit significantly different ${ }^{210} \mathrm{Po}$ activity concentrations compared to other fish species and therefore generic fish data (or ERICA reference organism fish data) might be used in lieu with reasonable confidence. In the comparisons of Cancer pagarus (+ related crab species) and all other types of crustaceans the null hypothesis could be rejected at the 0.05 significance level. It seems evident that different crustacean groups exhibit quite different activity concentrations of ${ }^{210}$ Po. For this particular case, generic data for crustaceans may not be appropriate surrogates for the subgroup RAP.

\section{Acknowledgments}

This work was supported by the Norwegian Research Council (NFR) and forms part of the INTRANOR (Impact assessment of elevated levels of natural/technogenic radioactivity on wildlife of the North) project, contract number 185134. The financial support of the NFR is gratefully acknowledged.

\section{References}

[1] Pentreath R.J., Journal of Radiological Protection 22, 45-56 (2002).

[2] ICRP, Annals of the ICRP 91, 201-266 (2003).

[3] Brown J.E., Jones S.R., Saxén R., Thørring H. and Vives i Batlle J., Journal of Radiological Protection 24, A63-A77 (2004).

[4] Larsson C.-M., An overview of the ERICA Integrated Approach to the assessment and management of environmental risks from ionising contaminants, Journal of Environmental Radioactivity (2008). doi:10.1016/j.jenvrad.2007.11.019. 
[5] ICRP, Annals of the ICRP (Volume) 37/2-4, 133-135 (2007).

[6] Brown J.E., Alfonso B., Avila R., Beresford N.A., Copplestone D., Pröhl G. and Ulanovsky A., The ERICA Assessment Tool. Journal of Environmental Radioactivity (2008). doi:10.1016/j.jenvrad.2008.01.008

[7] Harr M.E., Reliability-Based Design in Civil Engineering (McGraw-Hill, 1987).

[8] IAEA, Sediment distribution coefficients and Concentration Factors for biota in the Marine Environment, Technical Reports Series No. 422. (International Atomic Energy Agency, Vienna, 2004).

[9] Hosseini A., Thørring H., Brown J.E., Saxén R. and Ilus E., Transfer of radionuclides in aquatic ecosystems - default concentration ratios for aquatic biota in the Erica Tool, Journal of Environmental Radioactivity (2008). doi:10.1016/j.jenvrad.2008.01.012.

[10] Pröhl G., Brown J., Gomez-Ros J.-M., Jones S., Woodhead D., Vives J., Taranenko V. and Thørring H., Dosimetric models and data for assessing radiation exposure to biota, Deliverable Report 3 for the EC Project FASSET - Contract No. FIGE-CT-2000-00102 (Swedish Radiation Protection Authority, Stockholm, 2003).

[11] Chambers D.B., Osborne R.V. and Garva A.L., Journal of Environmental Radioactivity, 87, 1-14 (2006).

[12] Tracy B.L. and Thomas P.A., An appropriate weighting factor for the effects of alpha radiation on non-human biota, in: Proceedings from the International Conference on radioactivity in the environment, Monaco, 2002, edited by P. Børretzen, T. Jølle and P. Strand (Norwegian Radiation Protection Authority, Østerås, 2002), pp. 65-68 (2002).

[13] Cherry R.D. and Shannon L.V., Atom. Energy Rev. 12: 3-45 (1974). 